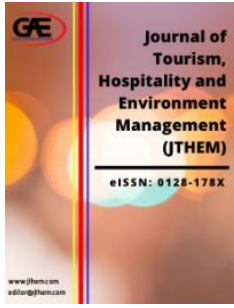

\author{
JOURNAL OF TOURISM, \\ HOSPITALITY AND \\ ENVIRONMENT MANAGEMENT \\ (JTHEM) \\ www.jthem.com
}

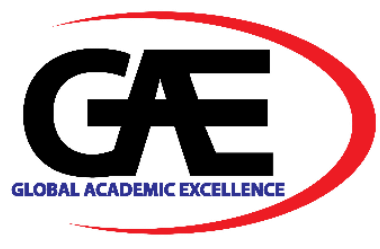

\title{
THE RELATIONSHIP BETWEEN WORKPLACE BULLYING AND JOB SATISFACTION IN OMAN'S HOTEL SECTOR: THE MEDIATING ROLE OF OCCUPATIONAL SELF-EFFICACY
}

\author{
Asma Shughail Aqib Al Hashimi ${ }^{*}$, Adi Anuar Azmin ${ }^{2}$ \\ 1 Faculty of Applied and Human Sciences, Universiti Malaysia Perlis, Malaysia \\ Email: asmashughail@studentmail.unimap.edu.my \\ 2 Faculty of Applied and Human Sciences, Universiti Malaysia Perlis, Malaysia \\ Email: adianuar@unimap.edu.my \\ Corresponding Author
}

\section{Article Info:}

Article history:

Received date: 23.06.2021

Revised date: 05.07.2021

Accepted date: 26.09.2021

Published date: 30.09.2021

\section{To cite this document:}

Al Hashimi, A. S. A., \& Azmin, A. A. (2021). The Relationship Between Workplace Bullying And Job Satisfaction In Oman's Hotel Sector: The Mediating Role Of Occupational Self-Efficacy. Journal of Tourism, Hospitality and Environment Management, 6 (24), 39-53.

DOI: 10.35631/JTHEM.624005.

This work is licensed under CC BY 4.0

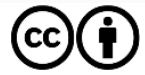

\begin{abstract}
:
An inclusive workplace helps in achieving effective performance at all organisational levels. Workplace bullying is recognised as a global phenomenon tremendously influencing self-efficacy and employees' job satisfaction. The current study aimed to examine the relationship between workplace bullying and job satisfaction with the mediating role of occupational self-efficacy in the hotel sector in Oman. The cross-sectional research was carried out in three hotels in Oman. The data were collected from 400 employees working in middle and low management in hotels in Oman. Additionally, data were gathered using the Negative Acts Questionnaire-Revised, the Occupational Self-Efficacy Scale, and the Generic Job Satisfaction Scale. Preliminary data analysis and regression analysis were performed using Statistical Package for Social Science (SPSS). Meditational analysis was conducted with PROCESS macro written by Hayes. The findings highlighted that workplace bullying correlates with job satisfaction positively and negatively with occupational self-efficacy. Occupational selfefficacy was negatively correlated with job satisfaction. Regression analysis showed that workplace bullying was a significant predictor of job satisfaction. However, occupational self-efficacy did not significantly mediate the relationship between workplace bullying and job satisfaction. The mediational analysis confirmed that occupational self-efficacy did not mediate the relationship between workplace bullying and job satisfaction. Management must develop and concentrate on building an inclusive work environment to reduce workplace bullying and harness occupational self-efficacy. Practical steps must be taken to deliver the interventions that can empower the employee to tackle workplace bullying and improves self-efficacy. This study also identified limitations and future research options.
\end{abstract}




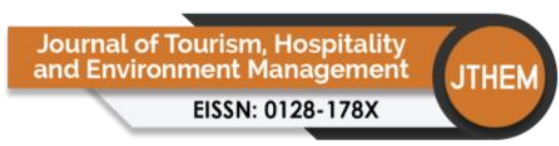

Volume 6 Issue 24 (September 2021) PP. 39-53 DOI 10/35631/JTHEM.624005

Keywords:

Workplace Bullying, Job Satisfaction, Occupational Self-Efficacy, Hotel Sector, Oman

\section{Introduction}

Workplace bullying at any level is a sign of poor management or leadership (Woodrow \& Guest, 2017). A great manager cares for every employee at work and makes them feel valued. Some managers allow personal relationships with employees to influence their interaction at the workplace. The least discriminatory acts attributed to the weak human errors perpetrated by a manager can be perceived as acts of bullying (Crystal, 2019). Although some employees are exceptional at work, managers may not appreciate them as they dislike the employees (Susan, 2019).

The Sultanate of Oman is an Islamic state with strict sharia laws observance (Krawietz, 2008). The country has an overwhelming number of immigrants who desperately migrate to the country in search of employment. They have distinct backgrounds, making them different in terms of social precisions (Das \& Gokhale, 2010). These employees often complain of being not entirely accepted in the workplace due to religion and complexion (Al-Maniri, Fochsen, Al-Rawas, \& De Costa, 2010). For instance, managers and clients in the hotel industry are likely to be mean and strict toward immigrant workers.

Workplace bullying in the Sultanate of Oman is widespread in many sectors and perpetuated differently by different people (Matei, 2019). The bullying act can be in the form of direct or indirect insults, mean comments, and discrimination based on performance or demographic differences (Rossheim, 2019). Some employees feel undervalued, not recognised or appreciated for what they do. Employees as human resources, a critical factor of production, can get discouraged, angry, or even disheartened (Pelletier, 2016) with the bullying.

Transferring workers between departments without consultation may be perceived as bullying (Matei, 2019). According to Landau (2017), bullying may also be perpetrated by excessive, unnecessary supervision at work. Human resource is very crucial to businesses. Thus, respecting the employees' interests in the best way possible is critical. Some employers use every chance to remind employees of their previous mistakes as a punch line (AL Hashmi \& Faizy, 2019).

According to Kurter (2019), employees need to develop resistance to survive when working in a bullying environment. Many ensure they do their job effectively and on time to avoid conflict with their employers (Laura, 2012). Confronting a manager can be disastrous and may lead to an employee being fired. The capability to adapt to workplace bullying is essential since an individual with higher authority may choose to treat employees wrongly.

Boosting employees' confidence at work through improving confidence and motivation is essential, leading to better production (Mahalanobis, 2018). Employees can interact and feel like part of the team. In an unhealthy bullying situation, employees feel left out and unwanted (Vartia-Väänänen, 2003). They may fail to associate themselves with the organisation, which is heartbreaking and discouraging. Workers who feel disconnected from the management and business organisation may feel like they may be easily laid off (Sanyal, Hisam, \& BaOmar, 


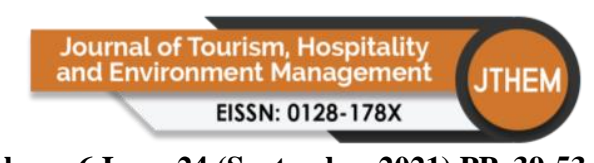

Volume 6 Issue 24 (September 2021) PP. 39-53 DOI 10/35631/JTHEM.624005 2018). A good employer nurtures the employees by positively encouraging them to boost their confidence and feel a part of the organisation.

Zapf et al. (2020) concluded that between 3 to $4 \%$ of workers had suffered severe forms of bullying at the workplace. About 9 to $15 \%$ have been occasionally subjected to bullying in the workplace. Many research highlighted that victims of workplace bullying have felt disgraced, depressed and guilty (Coyne, Seigne, \& Randall, 2000; Matthiesen \& Einarsen, 2001; Hogh, Mikkelsen, \& Hansen, 2012; Vaughan, 2012; Reknes et al., 2016).

Workplace bullying research did not begin with a particular theoretical approach based on domains. The concept has been examined in empirical models, which are only partially associated with various theoretical frameworks. Stress theories have been used to explain several sources and implications of bullying, such as the Job Demands-Resources framework (Baillien, Rodriguez-Muñoz, Van den Broeck, \& De Witte, 2011; Einarsen, Skogstad, Rørvik, Lande, \& Nielsen, 2018), cognitive activation theory of stress (Ursin \& Eriksen, 2004; Glambek, Einarsen, \& Helge, 2018) and trauma theory of Janoff-Bullman (Janoff-Bulman \& Frantz, 1996; Glambek et al., 2018).

Job satisfaction is a powerful indicator that is frequently used to assess the outcomes of various organisational processes, including organisational climate, management style and others (Judge, Thoresen, Bono, \& Patton, 2001; Petrović \& Ćurić, 2013). Researchers showed that bullying in the workplace was adversely linked to job satisfaction (Tepper, Duffy, Hoobler, \& Ensley, 2004; Bowling \& Beehr, 2006; Rodríguez-Muñoz, Baillien, De Witte, MorenoJiménez, \& Pastor, 2009). Giorgi, Shoss, and Leon-Perez (2015) suggested that a relative degree of job satisfaction might play a significant part in responding to bullying at the workplace. Job satisfaction has been identified in various tested models as an indigenous outcome of workplace bullying and moderation or mediation (Arenas et al., 2015; Giorgi et al., 2015).

The impact of bullying on job satisfaction is detrimental over the longer term. In a two-wave analysis, Tepper et al. (2004) asserted that abusive supervision adversely influenced job satisfaction in rounds 1 and 2. According to the abovementioned results, bullying in the workforce may be inferred as stripping away goals (Rodríguez-Muñoz et al., 2009) and decreasing job satisfaction.

The concept of workplace bullying copes with the occupational self-efficacy beliefs essential to preventing or facilitating the escalation of adverse behaviours into bullying. In its original definition, self-efficacy is a concept that relates to the belief that individuals are willing to organise their capacities and abilities to produce optimal results (Bandura, 1986). Thus, selfefficacy is an evolving concept today as one of the key factors of the phrase defined as the optimistic aspect of existence.

The concept of self-efficacy has been studied in various contexts, from school to career planning to controlling harmful emotions. In the workplace context, the possibility of the modulatory effect of self-efficacy on the negative impacts of emotionally charged jobs has been investigated in several studies (Heuven, Bakker, Schaufeli, \& Huisman, 2006). The researchers discovered that employees with high self-efficacy are much capable of coping with emotional interactions with employers than their low self-efficacy peers. According to the researchers, 


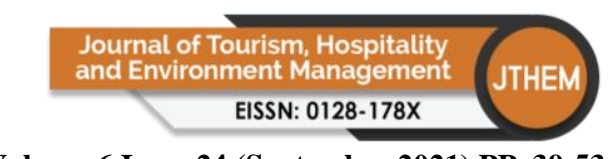

Volume 6 Issue 24 (September 2021) PP. 39-53

DOI 10/35631/JTHEM.624005

self-efficacy may allow people to prevent the difference between senses and feelings as they communicate with hostile or frustrated employers. Self-efficacy may play a crucial part in sustaining and improving positive emotional effects at work.

Studies have proved that individuals with high self-efficacy, instead of other less adaptive behaviours, such as depression or anxiety conditions, remain committed to meeting the high demands of their jobs (S. M. Jex \& Bliese, 1999). The association between bullying and mental health and intention to leave was partially brokered through self-efficacy (Hsieh, Wang, \& Ma, 2019). The implication of job insecurity on absenteeism and performance in service recovery was mediated partially by self-efficacy (Etehadi \& Karatepe, 2019). The role of mediation has also been studied in the public and sectors in the association between job uncertainty, job satisfaction, work engagement and well-being (Guarnaccia, Scrima, Civilleri, \& Salerno, 2018).

Occupational self-efficacy at the individual level offers better control on job-related issues, promotes physical and psychological well-being (Jones \& Fletcher, 2003). Nevertheless, numerous research discovered minimal support for potential associative variables, such as job control and adjustment assessed in job satisfaction (Terry \& Jimmieson, 1999).

Job satisfaction refers to a stable and enjoyable emotional state linked to triumphant task success and a standardised assessment of the success (Wilkin, 2013). Individuals with psychological needs met in the workplace have higher self-esteem and lower anxiety levels (Deci et al., 2001). In addition, self-efficacy is involved in higher performance (Schwoerer \& May, 1996) and improved job performance from an organisational perspective (Stajkovic \& Luthans, 1998). Salanova, Grau, and Martínez (2005) discovered that self-efficacy modulates the relationship between the demands experienced by staff in their work settings and the displayed type of coping behaviour. Another research investigated the predictive function of general self-efficacy on burnout and engagement (Durán, Extremera, Rey, Fernández-Berrocal, \& Montalbán, 2006), which underscores the importance and reach of the material of this investigation.

Based on the literature, workplace bullying is evidently a phenomenon and requires control for better job satisfaction. The function of occupational self-efficacy is crucial in managing job satisfaction in workplaces where bully occurs. Therefore, exploring workplace bullying from the self-efficacy context leading to job satisfaction is essential as self-efficacy instigates the personal capacity to deal with unfavourable events at the workplace (Salanova et al., 2005). The management of workplace bullying is possible via self-efficacy that promotes job satisfaction (Hsieh et al., 2019).

The present research attempts to offer empirical evidence on the association between occupational self-efficacy in the correlation between job satisfaction and workplace bullying. Similarly, the research aims to verify the possible mediating role of occupational self-efficacy, particularly to confirm whether subjects with more workplace bullying who show greater occupational self-efficacy have higher job satisfaction.

The following objectives were formulated on the basis of the current literature:

1. To evaluate the relationship between workplace bullying and job satisfaction among the middle and lower management in the hotel sector in Oman. 
2. To examine the mediated role of occupational self-efficacy between workplace bullying and job satisfaction among the middle and lower management in the hotel sector in Oman.

The theoretical framework below illustrates the association between the three variables. Workplace bullying is the independent variable, job satisfaction is the dependent variable, while occupational self-efficacy is the mediating variable. The mediating variable appears between the dependent and independent variables to explain the relationship mechanism between the two variables.

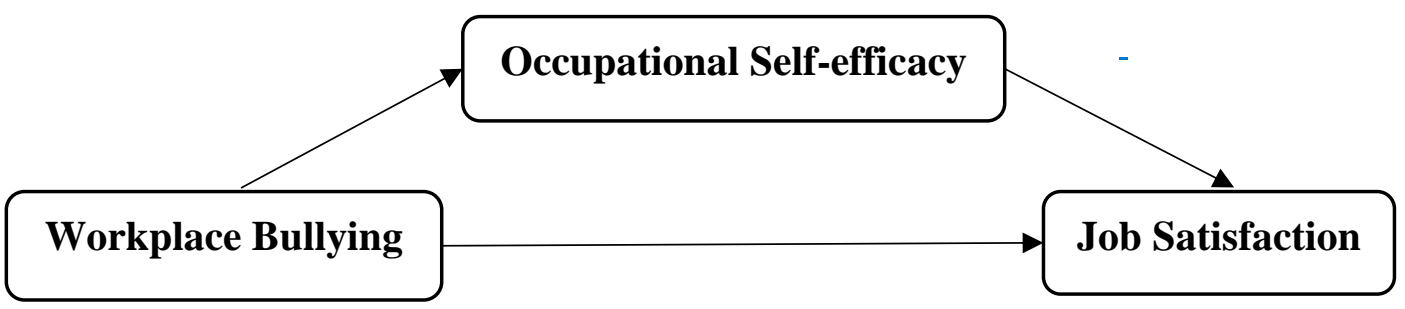

Figure 1. The Theoretical Framework of The Study

\section{Research Method}

Research method refers to research techniques, such as data collection method, research design, the target population, the location where the research takes place, the population sample size, and the statistical analysis methods used in the study (Kadam \& Joshi, 2019).

\section{Research Design}

A survey (cross-sectional) research design was employed in this research. This survey utilised qualitative and quantitative research methods to develop reliable and accurate findings and conclusions. A qualitative method was used to assess and understand the respondents' views concerning the implications of workplace bullying on job satisfaction. A quantitative method was used to analyse numerical data collected from the field to make inferential conclusions.

\section{Participants}

The survey was undertaken in Oman, focusing on the hotel industry, which offers services to clients. A total of 400 respondents were randomly selected from four major hotels, including Kempinski Hotel Muscat, W Muscat, JW Marriott Muscat, and Muscat Gate hotel. The participants were middle management (junior managers) and lower management (cooks, food servers, receptionists, and electricians). The researcher selected 100 participants randomly from each hotel belonging to different departments with assistance from the upper management. Research questions were subsequently developed according to the study objectives and hypotheses. The research questions were administered to the selected respondents through questionnaires. The research questions included:

Do you receive recognition for a well-done job?

Are you satisfied with the salaries and benefits you receive at work?

Does your supervisor at a time order you to work below your proficiency?

Do you, at times, get shifted at your workplace without your consultation?

Have you ever been bullied at work? 


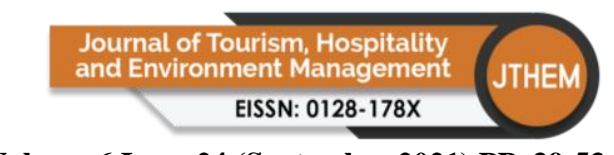

Volume 6 Issue 24 (September 2021) PP. 39-53

\section{Instrument}

DOI 10/35631/JTHEM.624005

Workplace Bullying Scale: Data for the present research were obtained by utilising the questionnaires adapted from the Negative Acts Questionnaire: NAQ-R (Einarsen, Hoel, \& Notelaers, 2009). A five-point Likert scale comprising from strongly agree to strongly disagree was employed. The NAQ has a reliability of .93.

Generic Job Satisfaction Scale: The job satisfaction scale could be employed for various occupational groups. This scale used a five-point Likert scale encompassing strongly agree to strongly disagree. The Cronbach's alpha for these items was .77 (Macdonald \& Maclntyre, 1997).

Occupational Self-Efficacy Scale: Schyns and Von Collani (2002) developed an extended version of the occupational self-efficacy scale. A simplified version with only eight elements was proven to be a reliable measure in a German sample. A five-point Likert scale was utilised for this scale covering strongly agree to strongly disagree. The short version has internal coherence with .86. A factor study discovered two factors, where one factor clarified $52.24 \%$ of the variance, while another indicated $25.08 \%$.

\section{Ethical Considerations}

Ethical considerations refer to the set rules and regulations for the researcher's consideration throughout the research process (Kadam \& Joshi, 2019). Prior discussion was undertaken, and permission was obtained from participants. The researcher made it clear that the information would not be used to sabotage the management or against the hotel. The participants were briefed about the survey and the importance of their participation. The participants were further instructed on the questionnaire and were requested not to disclose any personal information. These procedures were undertaken to assure the participants' confidentiality and enable them to provide accurate and appropriate responses without fear. The data collected from the questionnaires were then sorted, reviewed, and entered into SPSS for further analysis.

\section{Data Analysis}

The SPSS 24.0 was utilised to undertake data analysis. The participants' demographic information, including gender, age, and profession, were determined using descriptive statistics such as median, mode, and mean. Pearson correlation analysis was undertaken to determine the level of correlation between job satisfaction, workplace bullying, and occupational selfefficacy. A chi-square test was also conducted to identify any statistically significant relationship between the variables (Faryadi, 2019). Process mediation Hayes SPSS was utilised to examine occupational self-efficacy as a potential mediator in the association between workplace bullying and job satisfaction during the regression analysis. The significance level for all of the studies was set at 0.05 during the analyses.

\section{Results}

\section{Descriptive Statistics, Correlations and Regression}

\section{Descriptive Statistics}

This survey drew a total of 550 employees who were eligible to take part. A total of 472 participants completed the survey, yielding an $85.8 \%$ response rate or 400 valid and complete 
surveys. Descriptive statistics in Table 1 summarises the respondents' age. The minimum age observed among the participants was 20 years old, whereas the eldest participant was 56 years old. The mean age of the participants was 37.83 , proving that majority of the participants were youths.

The table below illustrates the participants' gender. Most respondents were female $(52.3 \%)$, while $47.8 \%$ were male respondents. The frequency table below shows the respondents' occupations. Out of the 400 respondents who participated in the survey, 25\% were cooks, $21.5 \%$ were receptionists at the hotels, $19.3 \%$ were junior managers, $18.3 \%$ were electricians, while $16.0 \%$ were food servers.

Table 1. Demographic Characteristics of the Participants

\begin{tabular}{cccccc}
\hline & $\mathbf{N}$ & $\mathbf{\%}$ & $\mathbf{N}$ & $\%$ \\
\hline Gender & & & Age & & \\
Male & 209 & 52.3 & $20-25$ years & 61 & 15.2 \\
Female & 191 & 47.8 & $26-30$ years & 66 & 16.6 \\
Total & 400 & 100 & $31-35$ years & 55 & 13.7 \\
& & & $36-40$ years & 44 & 11.0 \\
Occupation & & & $41-45$ years & 57 & 14.2 \\
Cook & 100 & 25.0 & $46-50$ years & 53 & 13.3 \\
Junior Manager & 77 & 19.3 & Above 50 years & 64 & 16.0 \\
Receptionist & 86 & 21.5 & Total & 400 & 100 \\
Electrician & 73 & 18.3 & & & \\
Food Server & 64 & 16.0 & & & \\
Total & 400 & 100 & & & \\
\hline
\end{tabular}

\section{Bullying at Work}

The following table shows whether the respondents had been bullied at work. Of all the 400 respondents, $14.0 \%$ highlighted that they had not been bullied. $18.0 \%$ reported mild bullying cases, whereas $17.8 \%$ were occasionally bullied. $18.8 \%$ had faced bullying several times per week while at work, $14.5 \%$ almost got bullied frequently, whereas $17.0 \%$ were bullied daily.

Table 2. Responses Frequency of Those Who Had Been Bullied at Work

\begin{tabular}{|c|c|c|c|c|c|c|c|}
\hline & Never & $\begin{array}{c}\text { Yes, } \\
\text { rarely }\end{array}$ & $\begin{array}{c}\text { Yes, } \\
\text { now and } \\
\text { then }\end{array}$ & $\begin{array}{c}\text { Yes, } \\
\text { several } \\
\text { times per } \\
\text { week }\end{array}$ & $\begin{array}{c}\text { Yes, } \\
\text { almost }\end{array}$ & $\begin{array}{c}\text { Yes, } \\
\text { daily }\end{array}$ & Total \\
\hline Frequency & 56 & 72 & 71 & 75 & 58 & 68 & 400 \\
\hline Percentage (\%) & 14.0 & 18.0 & 17.8 & 18.8 & 14.5 & 17.0 & 100 \\
\hline
\end{tabular}

These results can be further illustrated as shown in the graph bar below. 


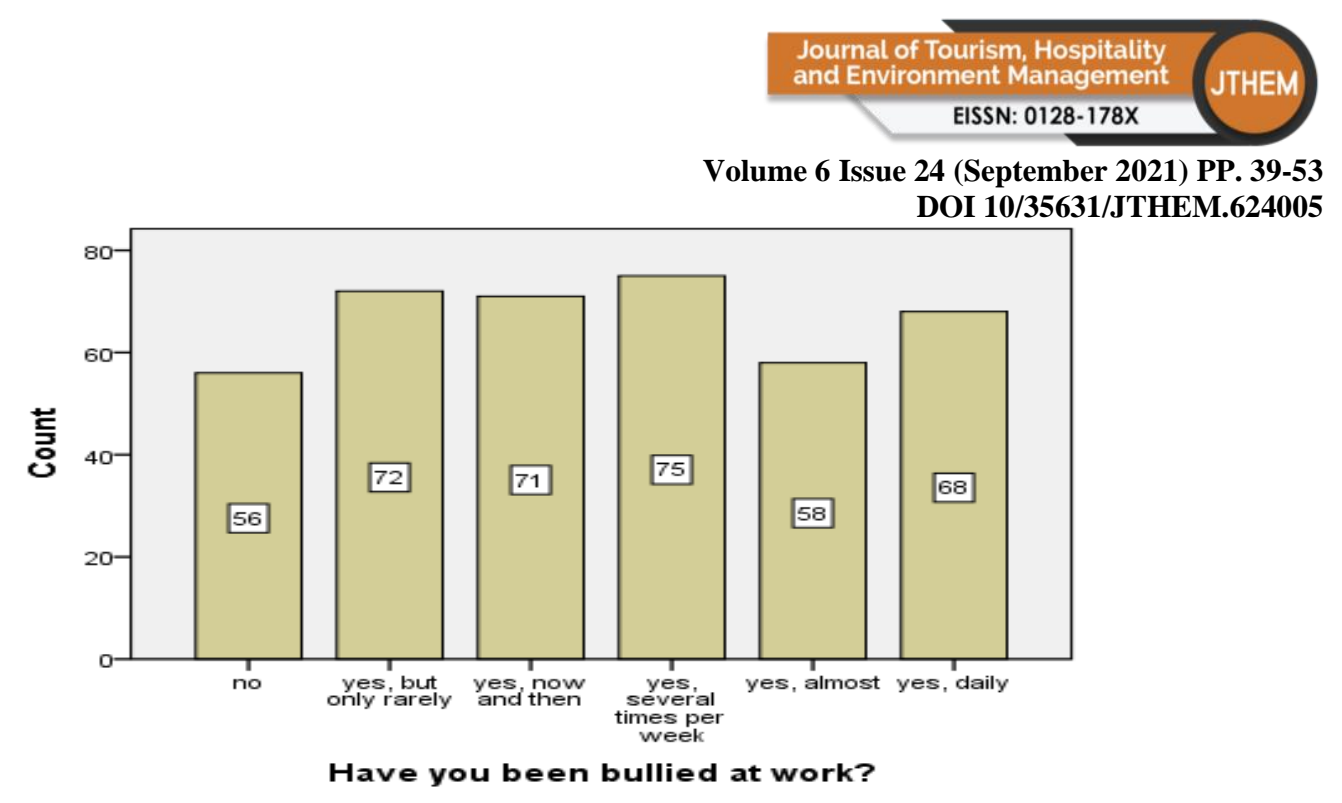

Figure 2. Frequency of Responses Among Those Who Had Been Bullied at Work

\section{A Chi-Square Test}

Hypothesis (I): Is There A Relationship Between Workplace Bullying And Job Satisfaction?

Null hypothesis: Bullying at the workplace is not associated with job satisfaction. Alternative: Bullying at the workplace is associated with job satisfaction.

Table 3. Chi-Square Results

\begin{tabular}{|c|c|c|c|}
\hline \multicolumn{4}{|c|}{ Chi-Square Tests } \\
\hline & Value & df & $\begin{array}{l}\text { Asymp. Sig. } \\
\text { (2-sided) }\end{array}$ \\
\hline Pearson Chi-Square & $974.989^{a}$ & 380 & .000 \\
\hline Likelihood Ratio & 340.703 & 380 & .927 \\
\hline $\begin{array}{l}\text { Linear-by-Linear } \\
\text { Association }\end{array}$ & 34.201 & 1 & .000 \\
\hline$N$ of Valid Cases & 400 & & \\
\hline
\end{tabular}

According to the preceding chi-square statistics, the chi-square coefficient is 974.989 with 380 degrees of freedom and a p-value of 0.00 . The null hypothesis was rejected because $p=$ $0.00<0.05$. Conclusively, an association exists between bullying at the workplace and job satisfaction, denoting that bullying at the workplace impacts job satisfaction.

\section{Correlation Analysis}

Table 4. Means, Standard Deviations and Correlation for The Variables $(N=400)$ in The Research on Workplace Bullying, Occupational Self-Efficacy, and Job Satisfaction among The Low and Middle Management in The Hotel Sector.

\begin{tabular}{|c|c|c|c|c|c|c|}
\hline \multicolumn{2}{|c|}{} & $\begin{array}{c}\text { Job } \\
\text { Satisfactio } \\
\mathrm{n}\end{array}$ & $\begin{array}{c}\text { Workplace } \\
\text { Bullying }\end{array}$ & $\begin{array}{c}\text { Occupation } \\
\text { al Self- } \\
\text { Efficacy }\end{array}$ & Mean & $\begin{array}{c}\text { Standard } \\
\text { Deviatio } \\
\mathrm{n}\end{array}$ \\
\hline $\begin{array}{c}\text { Job } \\
\text { Satisfaction }\end{array}$ & $\begin{array}{c}\text { Pearson } \\
\text { Correlation }\end{array}$ & 1 & $.468^{* *}$ & .088 & 3.0775 & .59184 \\
\hline
\end{tabular}




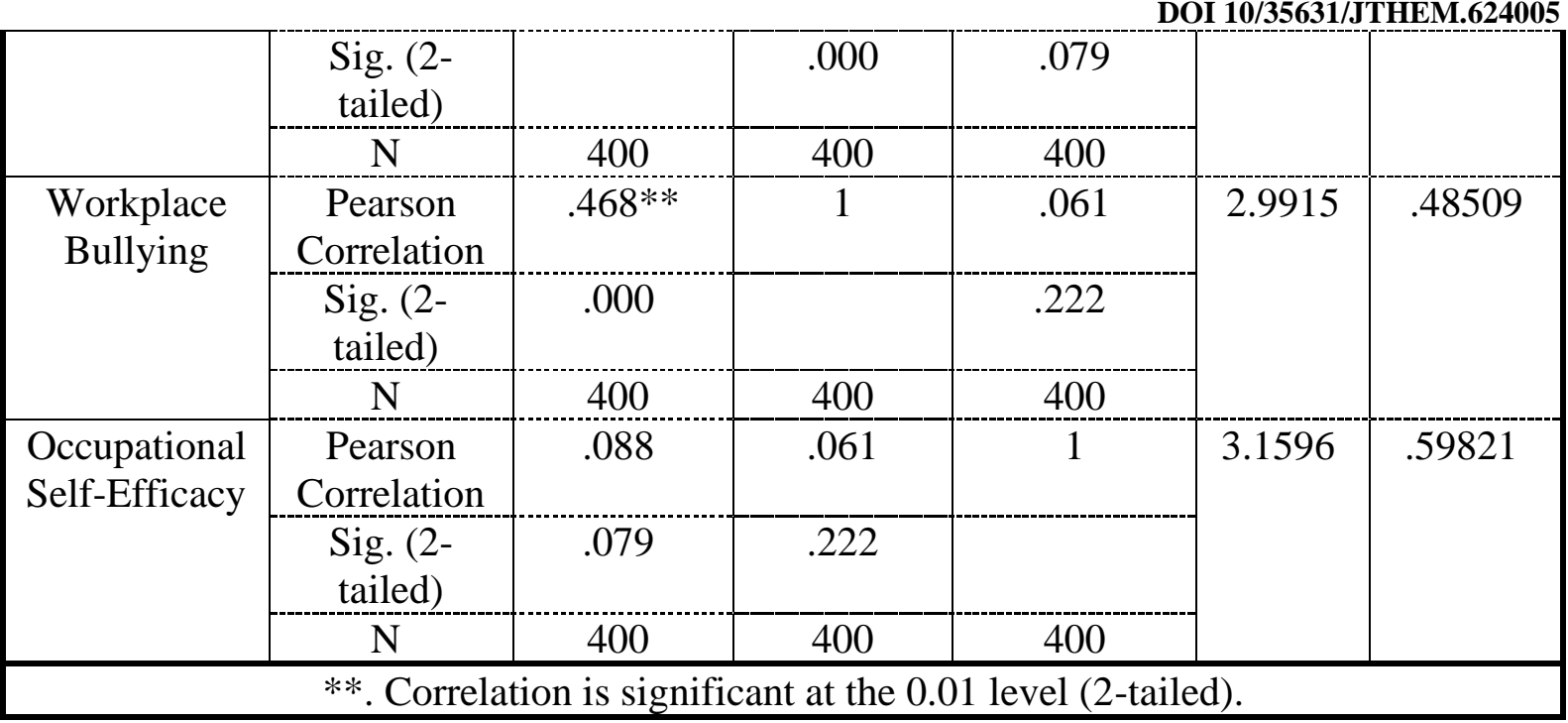

Correlation analysis (Refer to Table 4) showed that workplace bullying was positively correlated with job satisfaction $(\mathrm{r}=0.468, \mathrm{p}<0.001)$, but negatively associated with occupational self-efficacy $(\mathrm{r}=-0.061, \mathrm{p}<0.001)$. Occupational self-efficacy was negatively associated with job satisfaction $(r=0.088, \mathrm{p}<0.001)$.

Hypothesis (ii): Is there a significant mediating effect of occupational self-efficacy on the relationship between workplace bullying and job satisfaction?

Null hypothesis: Occupational self-efficay does not significantly mediate the relationship between workplace bullying and job satisfaction

Alternative: Occupational self-efficay significantly mediates the relationship between workplace bullying and job satisfaction.

The mediational analysis for the current study was performed with the SPSS macro authored by Hayes (2002). The SPSS macro performed three analyses with the 5000 samples bootstrapping procedure. The first test showed that workplace bullying could explain $6 \%$ of the change in occupational self-efficacy among the study samples. The path values demonstrated that workplace bullying $(\beta=0.075, \mathrm{t}=1.223, \mathrm{p}=0.221)$ insignificantly influences occupational self-efficacy (Refer to Table 5).

Table 5. Regression Analysis

\begin{tabular}{|l|c|c|c|c|l|l|}
\hline Path & Coefficient & T-value & P-value & LLCI & ULCI & Decision \\
\hline \multicolumn{2}{|c|}{ Direct Path } & & & & & \\
\hline WBY $\rightarrow$ OSE & 0.075 & 1.223 & 0.221 & -0.458 & 0.1968 & Reject \\
\hline WBY $\rightarrow$ JST & 0.570 & 10.557 & 0.000 & 0.464 & 0.677 & Accept \\
\hline \multicolumn{2}{|c|}{} & & & & & \\
\hline \multicolumn{2}{|c|}{ Indirect Path } & & & & & \\
\hline WBY $\rightarrow$ JST & 0.566 & 10.465 & 0.000 & 0.459 & 0.673 & Accept \\
\hline OSE $\rightarrow$ JST & 0.058 & 1.340 & 0.180 & -0.027 & 0.145 & Reject \\
\hline
\end{tabular}

Note: WBY: Workplace bullying, OSE: Occupational self-efficacy, JST: Job satisfaction, LLCI: Lower-level confidence interval, ULCI: Upper-level confidence interval 


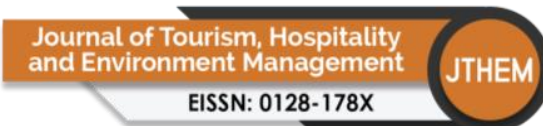

Volume 6 Issue 24 (September 2021) PP. 39-53

DOI 10/35631/JTHEM.624005

The second test showed that workplace bullying could explain $46.7 \%$ of changes in job satisfaction among the study samples. The path values pointed that workplace bullying $(\beta=$ $0.570, \mathrm{t}=10.557, p=0.000)$ significantly influence job satisfaction occupational self-efficacy (Refer to Table 5).

The third test showed that workplace bullying and occupational self-efficacy could explain the $47.1 \%$ of changes in job satisfaction among the study samples. The path value pointed that workplace bullying $(\beta=0.566, \mathrm{t}=10.465, p=0.000)$ significantly influence job satisfaction occupational self-efficacy (Refer to Table 5). However, occupational self-efficacy $(\beta=0.058$, $\mathrm{t}=1.340, p=0.180)$ insignificantly influence the job satisfaction.

The result depicts the insignificant effect of occupational self-efficacy between workplace bullying and job satisfaction. The total effect of workplace bullying on job satisfaction showed that the effect was significant. Nevertheless, the direct effect was significant. The results depicted that occupational self-efficacy did not significantly mediate the association between workplace bullying and job satisfaction. The indirect effect was also insignificant (Refer to Table 6). Thus, the null hypothesis was accepted

Table 6. Mediational Analysis Effect Sizes

\begin{tabular}{|l|l|l|l|l|l|l|}
\hline & Effect & SE & T & P & LLCI & ULCI \\
\hline Total effect & 0.570 & 0.541 & 10.557 & 0.000 & 0.464 & 0.676 \\
\hline Direct effect & 0.566 & 0.541 & 10.456 & 0.000 & 0.459 & 0.672 \\
\hline Indirect effect & 0.004 & 0.005 & 1.223 & 0.221 & -0.004 & 0.017 \\
\hline
\end{tabular}

Note: SE: Standard Error, T: t-value, P: p-value, LLCI: Lower-level confidence interval, ULCI: Upper-level confidence interval.

\section{Discussion}

The study results supported the hypotheses in the present research. The results aligned with prior research linking workplace bullying to job satisfaction. Bullied employees tend to have physical and mental health issues than employees who are not bullied (Dehue, Bolman, Völlink, \& Pouwelse, 2012; Verkuil, Atasayi, \& Molendijk, 2015). Participants who indicated they had been subjected to extensive workplace bullying were more likely to quit (Johnson \& Rea, 2009; Longo, 2012; Tsai, Han, Chen, \& Chou, 2014).

Conclusively, workplace bullying was found to impact job satisfaction from the chi-square tests undertaken to examine the associations between job satisfaction, bullying at the workplace, and occupational self-efficacy. The results indicated a statistically significant chisquare test result with a Pearson chi-square value of 974.989 with 380 degrees of freedom and a significant $\mathrm{p}$-value of $0.00<0.05$. The Pearson correlated test displayed that workplace bullying positively correlates with job satisfaction $(\mathrm{r}=0.4768, \mathrm{p}<0.001)$. The regression test also revealed a significant direct relationship between job satisfaction and workplace bullying with a p-value $=.0000$

Another goal of this research was to determine whether occupational self-efficacy played a role in mediating the association between job satisfaction and workplace bullying. The regression test findings did not support the hypothesis, revealing that self-efficacy has no significant indirect influence on workplace bullying and job satisfaction. The current study finding highlighted that employee self-efficacy did not significantly influence job satisfaction. The results showed that workplace bullying and job satisfaction management do not require 


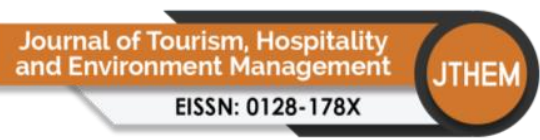

Volume 6 Issue 24 (September 2021) PP. 39-53 DOI 10/35631/JTHEM.624005

personal capacities but organisational support. The organisational facilitation and support harness the perception of self-efficacy and a sense of job satisfaction (Crystal, 2019). The workplace environment requires intervention from the management and basic code of ethics to manage the negative workplace behaviours and effectively manage positive organisational psychology.

Based on the results, employers are recommended to look for ways to maintain communication with the employees. A platform should be created to allow employees to air their views to reduce bullying at the workplace and contribute significantly to job satisfaction (Kurter, 2019). Additionally, employers should also create competition and promotion apt for employees. This action recognises employees' efforts and hard work, which minimises bullying and ensures job satisfaction at the workplace (Matei, 2019). In addition, Matei (2019) stated that employees require satisfaction but within the justified limits to perform well at the workplace. The managers and supervisors should set reasonable deadlines for employees to accomplish their duties. Moreover, the employers should set reasonable deadlines to develop a sound working system, which reduces time wastage and confusion among the employees to save time and reduce pressure created on the employees. Thus, bullying at the workplace will be reduced, and job satisfaction will be ensured (Kurter, 2019).

\section{Conclusion}

This research explored the association between workplace bullying and job satisfaction among employees from the hotel sector in Muscat, Oman. The present research also extended previous studies by emphasising the factors protecting employees' self-efficacy from workplace bullying and the adverse effects on their job. The findings indicated that workplace bullying significantly predicted job satisfaction.

The association between occupational self-efficacy and job satisfaction was not mediated significantly. Appropriate interventions must be specifically built to improve employees' selfefficacy in their careers to help them deal with challenging circumstances and protect against the adverse effects of bullying in the workplace. Further study is required to examine the nature, triggers and protective factors of workplace bullying to minimise the negative consequences.

The current research contributes to the conceptual underpinnings of the association between workplace bullying and job satisfaction. Workplace bullying was found to impact job satisfaction. Thus, management of workplace bullying is necessary for effective job performance and satisfaction. Management needs to stratagem and coach the workforce to empower them effectively. Empowering the employees can reduce the incidents of workplace bullying and instigate occupational self-efficacy in harnessing job satisfaction (Susan et al., 2019). Future research needs to comprehensively examine the role of self-efficacy in reducing workplace bullying and increase job satisfaction. Self-efficacy provides the opportunity for possible interventions of workers to foster the sense of personal agency and face job challenges with a more active and responsible approach. Thus, employees will empower their works and build an inclusive culture, enabling superior work performance. Positive psychology at the workplace is not only the workforce's duty. The top management needs to closely examine the matter and build a culture of trust and inclusiveness to reduce the impact of workplace bullying to promote self-efficacy and job satisfaction. Future research should examine the workplace culture on workplace bullying and job satisfaction. 


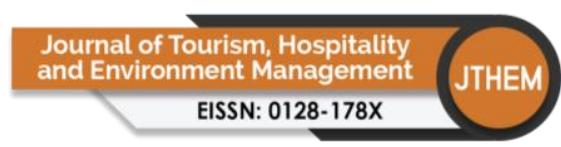

Volume 6 Issue 24 (September 2021) PP. 39-53 DOI 10/35631/JTHEM.624005

\section{References}

Al-Maniri, A., Fochsen, G., Al-Rawas, O., \& De Costa, A. (2010). Immigrants and health system challenges to TB control in Oman. BMC health services research, 10(1), 1-8.

AL Hashmi, O., \& Faizy, S. A. (2019). Employment and Labour Law in Oman. Global Legal Insights.

Arenas, A., Giorgi, G., Montani, F., Mancuso, S., Perez, J. F., Mucci, N., \& Arcangeli, G. (2015). Workplace bullying in a sample of Italian and Spanish employees and its relationship with job satisfaction, and psychological well-being. Frontiers in Psychology, 6, 1912.

Baillien, E., Rodriguez-Muñoz, A., Van den Broeck, A., \& De Witte, H. (2011). Do demands and resources affect target's and perpetrators' reports of workplace bullying? A twowave cross-lagged study. Work \& Stress, 25(2), 128-146.

Bandura, A. (1986). Social foundations of thought and action. Englewood Cliffs, 1986, 23-28.

Bowling, N. A., \& Beehr, T. A. (2006). Workplace harassment from the victim's perspective: a theoretical model and meta-analysis. Journal of Applied Psychology, 91(5), 998.

Coyne, I., Seigne, E., \& Randall, P. (2000). Predicting workplace victim status from personality. European Journal of Work and Organizational Psychology, 9(3), 335-349.

Crystal, R. (2019). How to identify and manage workplace bullying. Retrieved July, 17,2020, from https://www.healthline.com/health/workplace-bullying\#What-is-workplacebullying?

Das, K. C., \& Gokhale, N. (2010). Omanization policy and international migration in Oman. Middle East Institute.

Deci, E. L., Ryan, R. M., Gagné, M., Leone, D. R., Usunov, J., \& Kornazheva, B. P. (2001). Need satisfaction, motivation, and well-being in the work organizations of a former eastern bloc country: A cross-cultural study of self-determination. Personality and Social Psychology Bulletin, 27(8), 930-942.

Dehue, F., Bolman, C., Völlink, T., \& Pouwelse, M. (2012). Coping with bullying at work and health related problems. International Journal of Stress Management, 19(3), 175.

Durán, M. A., Extremera, N., Rey, L., Fernández-Berrocal, P., \& Montalbán, F. M. (2006). Predicting academic burnout and engagement in educational settings: Assessing the incremental validity of perceived emotional intelligence beyond perceived stress and general self-efficacy. Psicothema, 18, 158-164.

Einarsen, S., Hoel, H., \& Notelaers, G. (2009). Measuring exposure to bullying and harassment at work: Validity, factor structure and psychometric properties of the Negative Acts Questionnaire-Revised. Work \& Stress, 23(1), 24-44.

Einarsen, S., Skogstad, A., Rørvik, E., Lande, A. B., \& Nielsen, M. B. (2018). Climate for conflict management, exposure to workplace bullying and work engagement: a moderated mediation analysis. The International Journal of Human Resource Management, 29(3), 549-570.

Etehadi, B., \& Karatepe, O. M. (2019). The impact of job insecurity on critical hotel employee outcomes: The mediating role of self-efficacy. Journal of Hospitality Marketing \& Management, 28(6), 665-689.

Faryadi, Q. (2019). PhD thesis writing process: A systematic approach-How to write your methodology, results and conclusion. Online Submission, 10, 766-783.

Giorgi, G., Shoss, M. K., \& Leon-Perez, J. M. (2015). Going beyond workplace stressors: Economic crisis and perceived employability in relation to psychological distress and job dissatisfaction. International Journal of Stress Management, 22(2), 137. 


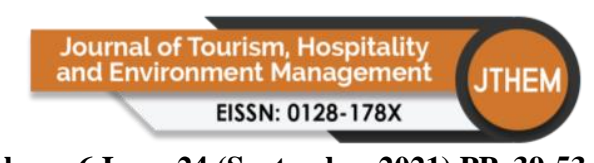

Volume 6 Issue 24 (September 2021) PP. 39-53

DOI 10/35631/JTHEM.624005

Glambek, M., Einarsen, S., \& Helge, H. (2018). The sources, prevalence, and consequences of bullying in the workplace Violence and abuse in and around organisations (pp. 224251): Routledge.

Guarnaccia, C., Scrima, F., Civilleri, A., \& Salerno, L. (2018). The role of occupational selfefficacy in mediating the effect of job insecurity on work engagement, satisfaction and general health. Current Psychology, 37(3), 488-497.

Heuven, E., Bakker, A. B., Schaufeli, W. B., \& Huisman, N. (2006). The role of self-efficacy in performing emotion work. Journal of vocational behavior, 69(2), 222-235.

Hogh, A., Mikkelsen, E. G., \& Hansen, A. M. (2012). Impact of bullying on workers. In N. Tehrani (Ed.), Workplace bullying: Symptoms and solutions (pp. 21-34): Routledge/Taylor \& Francis Group

Hsieh, Y. H., Wang, H. H., \& Ma, S. C. (2019). The mediating role of self-efficacy in the relationship between workplace bullying, mental health and an intention to leave among nurses in Taiwan. International journal of occupational medicine and environmental health, 32(2), 245-254.

Janoff-Bulman, R., \& Frantz, C. M. (1996). The loss of illusions: The potent legacy of trauma. Journal of Loss \& Trauma, 1(2), 133-150.

Jex, S. M., \& Bliese, P. D. (1999). Efficacy beliefs as a moderator of the impact of work-related stressors: a multilevel study. Journal of Applied Psychology, 84(3), 349.

Jex, S. M., Bliese, P. D., Buzzell, S., \& Primeau, J. (2001). The impact of self-efficacy on stressor-strain relations: Coping style as an explanatory mechanism. Journal of Applied Psychology, 86(3), 401.

Johnson, S. L., \& Rea, R. E. (2009). Workplace bullying: concerns for nurse leaders. The Journal of Nursing Administration, 39(2), 84-90.

Jones, F., \& Fletcher, B. C. (2003). Job control, physical health and psychological well-being The handbook of work and health psychology (Vol. 121).

Judge, T. A., Thoresen, C. J., Bono, J. E., \& Patton, G. K. (2001). The job satisfaction-job performance relationship: A qualitative and quantitative review. Psychological bulletin, 127(3), 376.

Kadam, A., \& Joshi, S. (2019). Introduction to design dissertation \& research methodology.

Krawietz, B. (2008). Islam and the rule of law: between Sharia and secularization: KonradAdenauer-Stiftung.

Kurter, H. L. (2019). Workplace bullying: 4 steps to overcome it and fight back. Retrieved July 17, 2020, from https://www.forbes.com/sites/heidilynnekurter/2019/07/05/workplacebullying-4-steps-to-overcome-it-and-fight-back/\#3062ad1d4a50

Landau, P. (2017). Bullying at work: your legal rights. Retrieved July 17, 2020, from https://www.theguardian.com/careers/2017/mar/29/bullying-at-work-your-legal-rights

Laura, W. (2012). Strategies to Combat Workplace Bullying. Retrieved July 18, 2020, from https://www.ehstoday.com/training-and-engagement/article/21915457/5-strategies-tocombat-workplace-bullying

Longo, J. (2012). Bullying in the workplace: Reversing a culture: American Nurses Association/Nursebooks. org.

Macdonald, S., \& Maclntyre, P. (1997). The generic job satisfaction scale: Scale development and its correlates. Employee Assistance Quarterly, 13(2), 1-16.

Mahalanobis, S. (2018). Oman- Positivity at the workplace. Retrieved Feburary 6, 2018, from https://menafn.com/qn_news_story_s.aspx?storyid=1096951258\&title=Oman-

Positivity-at-the-workplace 


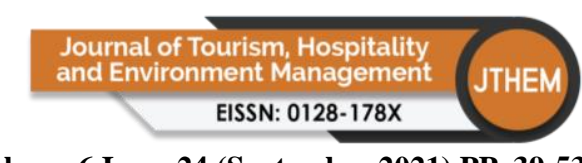

Volume 6 Issue 24 (September 2021) PP. 39-53 DOI 10/35631/JTHEM.624005

Matei, A. (2019). You're not alone: how to survive your horrible boss-Working under a bully can do real damage to your mental health. But there are ways to protect yourself. Retrieved July 1, 2020, from https://www.theguardian.com/lifeandstyle/2019/nov/19/how-to-deal-with-bad-bosses

Matthiesen, S. B., \& Einarsen, S. (2001). MMPI-2 configurations among victims of bullying at work. European Journal of Work and Organizational Psychology, 10(4), 467-484.

Pelletier, P. (2016). Workplace bullying prevention, management and elimination strategies for human resource professionals. Retrieved Feburary, 2016, from http://www.paulpelletierconsulting.com/wp-content/uploads/2018/03/HR-USArticle.pdf

Petrović, I. B., \& Ćurić, M. (2013). A comparison of web-based and paper-and-pencil job satisfaction surveys. Suvremena psihologija, 16(2), 155-168.

Reknes, I., Einarsen, S. V., PALLESEN, S., Bjorvatn, B., Moen, B. E., \& Magerøy, N. (2016). Exposure to bullying behaviors at work and subsequent symptoms of anxiety: the moderating role of individual coping style. Industrial health, 2015-0196.

Rodríguez-Muñoz, A., Baillien, E., De Witte, H., Moreno-Jiménez, B., \& Pastor, J. C. (2009). Cross-lagged relationships between workplace bullying, job satisfaction and engagement: Two longitudinal studies. Work \& Stress, 23(3), 225-243.

Rossheim, J. (2019). The cost of toxic cultures. Retrieved July 17, 2020, from https://www.workhuman.com/resources/globoforce-blog/the-cost-of-toxic-cultures\#

Salanova, M., Grau, R. M., \& Martínez, I. M. (2005). Demandas laborales y conductas de afrontamiento: el rol modulador de la autoeficacia profesional. Psicothema, 17(3), 390395.

Sanyal, S., Hisam, M. W., \& BaOmar, Z. A. (2018). Loss of job security and its impact on employee performance: A study in Sultanate Of Oman. International Journal of Innovative Research \& Growth, 6(7), 201-212.

Schwoerer, C. E., \& May, D. R. (1996). Age and work outcomes: The moderating effects of self-efficacy and tool design effectiveness. Journal of Organizational Behavior, 17(5), 469-487.

Schyns, B., \& Von Collani, G. (2002). A new occupational self-efficacy scale and its relation to personality constructs and organizational variables. European Journal of Work and Organizational Psychology, 11(2), 219-241.

Stajkovic, A. D., \& Luthans, F. (1998). Self-efficacy and work-related performance: A metaanalysis. Psychological bulletin, 124(2), 240.

Susan, M. H. (2019). Reasons why your employees may hate you: Learn ways to regain employee respect and trust. Retrieved 17, July 2019, from https://www.thebalancecareers.com/why-employees-hate-you-1917713

Tepper, B. J., Duffy, M. K., Hoobler, J., \& Ensley, M. D. (2004). Moderators of the relationships between coworkers' organizational citizenship behavior and fellow employees' attitudes. Journal of Applied Psychology, 89(3), 455.

Terry, D. J., \& Jimmieson, N. L. (1999). Work control and employee well-being: A decade review. International Review of Industrial and Organizational Psychology 14, 95-148.

Tsai, S. T., Han, C. H., Chen, L. F., \& Chou, F. H. (2014). Nursing workplace bullying and turnover intention: an exploration of associated factors at a medical center in Southern Taiwan. Hu Li Za Zhi, 61(3), 58.

Ursin, H., \& Eriksen, H. R. (2004). The cognitive activation theory of stress. Psychoneuroendocrinology, 29(5), 567-592. 
Vartia-Väänänen, M. (2003). Workplace bullying: A study on the work environment, wellbeing and health. University of Helsinki.

Vaughan, S. (2012). Ya'makasi or the art of displacement in the corporate world: A target's perspective on the impact of workplace bullying. In N.Tehrani (Ed.), Workplace bullying: Ssmptoms and solutions (pp. 51-66). London, UK: Routledge.

Verkuil, B., Atasayi, S., \& Molendijk, M. L. (2015). Workplace bullying and mental health: a meta-analysis on cross-sectional and longitudinal data. PloS one, 10(8), e0135225.

Wilkin, C. L. (2013). I can't get no job satisfaction: Meta-analysis comparing permanent and contingent workers. Journal of Organizational Behavior, 34(1), 47-64.

Woodrow, C., \& Guest, D. E. (2017). Leadership and approaches to the management of workplace bullying. European Journal of Work and Organizational Psychology, 26(2), 221-233.

Zapf, D., Escartin, J., Scheppa-Lahyani, M., Einarsen, S. V., Hoel, H., \& Vartia, M. (2020). Empirical findings on prevalence and risk groups of bullying in the workplace Bullying and harassment in the workplace (pp. 105-162): CRC Press. 